\title{
Built environment and potential job accessibility effects of road pricing: a spatial econometric perspective
}

\author{
Submitted by \\ Shaopeng ZHONG* \\ Assistant Professor \\ School of Transportation and Logistics \\ Dalian University of Technology, Dalian 116024, China \\ szsp001@163.com \\ Tel: +86-411-84771069 \\ Max BUSHELL \\ Transportation Planner \\ Orange County, NC Department of Planning and Inspections \\ 131 W Margaret Ln, \\ Hillsborough, NC 27278 \\ maxbushell@gmail.com \\ Tel: +1-336-4209640 \\ Corresponding Author
}

1

(C) 2017. This manuscript version is made available under the Elsevier user license http://www.elsevier.com/open-access/userlicense/1.0/ 


\title{
Built environment and potential job accessibility effects of road pricing: a spatial econometric perspective
}

\begin{abstract}
This paper analyzes the impacts of the built environment (BE) as it relates to the potential job accessibility (PJA) effects of road pricing. The relationships between the BE elements and PJA under a road charging policy are established using a spatial econometric approach, which uses an integrated land use and transportation model (TRANUS model) and a spatial lag model (SLM). With the intent of further analyzing the differences in the PJA effects of road pricing on traffic analysis zones (TAZs) that contain different combinations of BE elements, a quantitative classification method combining factor and cluster analysis is applied. This will quantitatively categorize TAZs inside and outside the tolled areas. In exploring the relationship between changes in PJA and the road pricing policy, we found the spatial autocorrelation coefficient to be negative. This result suggests that we are unable to increase the PJA of all the regions through road pricing, but rather affect a redistribution of PJA between different regions. Results also indicate that the impacts of road charging on PJA are associated with urban BE elements. Moreover, such effects are the common result of specific characteristics of the BE. The higher the number of jobs, the better the public transportation conditions, and the better the street design (high densities of street and intersections), the less the region will be negatively influenced by a road charging policy, and vice versa. To avoid the negative effects of road pricing on PJA prior to the launch of such a policy, cities should improve public transportation networks and enhance the street design of the road pricing policy areas, especially the toll ring periphery area.
\end{abstract}

Keywords: Cordon-based road pricing; Potential job accessibility; Spatial lag model; Land use and transportation interaction model; Factor analysis; Cluster analysis

\section{Introduction}

More and more cities are considering imposing road pricing schemes to reduce traffic congestion and enhance the efficiency and performance of transport systems (Zhong et al., 2017). With the intention of creating a more reasonable road pricing policy, our aim is to comprehensively evaluate the impact of a road pricing policy on urban systems before the introduction of such a policy. Road pricing schemes can be divided into two distinct types: mobility-based road pricing and accessibility-based road pricing. Mobility refers to the ease of movement. Accessibility, on the other hand, refers to the ease of arriving at activities (Levine and Garb, 2002). The difference between these two concepts as they relate to road pricing policy is that the goal of mobility-based road pricing is to reduce the travel cost per kilometer, while accessibility-based road pricing reduces the travel cost per activity. In the field of modern transportation planning, transportation is generally considered a "derived demand." That is, in order to participate in various activities, which are usually distributed in different parts of the city, travelers have to overcome the spatial distances between different activities through various transport modes. Therefore, under the framework of "derived demand," a successful road pricing policy should be oriented to enhance the accessibility of the region, rather than simply improving mobility. In recent years, decision-makers and scholars have been increasingly interested in the effects of road charging on regional accessibility, especially on potential job accessibility (PJA) (Condeço-Melhorado et al., 2011; Levine and Garb, 2002; Sánchez-Mateos et al., 2014; Wang et al., 2015).

Accessibility is often defined as the ease by which activities may be reached from a location employing a specific transport mode (Dalvi and Martin, 1976). Therefore, as indicated in the above definition, accessibility is actually a common "product" of land use and transport systems. In general, holding everything else equal, the higher the number of jobs combined with lower travel costs, the higher the PJA of the region. Keeping this in mind, an improvement in regional transportation infrastructure, such as road construction, will reduce travel time and change the PJA in that region. However, the impacts of road pricing on regional PJA are generally complex and vary depending on the particular built environment attributes of the region. This is because road pricing will not only stimulate a variety of changes in people's short term travel behavior and 
affect travel time and level of service of the transportation network, but also influence (re)location choices of firms or households, such as work or residential locations in the long term (Tillema et al., 2010a). Therefore, the launch of road user charges could change both the distribution of jobs and the performance of the transport system, and eventually have a significant effect on the PJA of the region. To date, the influence of road tolls on the PJA of regions with different built environments is not clear. In order to avoid the negative influences of a charging policy on PJA and regional economies, it is necessary to explore this issue in depth.

This study investigates the impact of road user charges on PJA at the zonal level in different spatial typologies in Jiangyin. There are two goals of this paper. The first is to examine the influences of road charging on future PJA based on the existing built environment of the region and evaluate the relationships between each built environment element and the PJA effects of road charging. The second aim is to further analyze the combined effects of different built environment factors on the PJA effects of road pricing. To achieve these goals, a series of models and techniques are employed, including a land use and transportation interaction (LUTI) model, data reduction technique, spatial lag model (SLM), and data classification technique.

The above mentioned models and techniques are related to each other. Each model or technology will be used as the basis for the research of the next model or technology. Specifically, as shown in Figure 1, the methodology used in this paper consists of the following steps. First, in order to reflect the interaction between land use and transportation, a LUTI model is employed to simulate the influences of road pricing on the future development of the region, and further estimate the PJA and other land use and transportation indicators under different road pricing schemes. These results will provide basic data for the following steps. Subsequently, to reduce the redundancy and inter-relatedness of the original data, we use factor analysis to compress the original variables and extract the basic elements of the built environment. On this basis, combined with the results obtained by the LUTI model, a spatial econometric approach is then applied to analyze the spatial effects of road pricing on PJA. Finally, to distinguish the impacts of road pricing on PJA and also interpret the spatial regression outcomes, a cluster analysis technique is adopted to quantitatively classify traffic analysis zones (TAZs) with different built environments.

\section{Figure 1 Model framework}

To the best of our knowledge, this paper is the first attempt to use a spatial econometric approach to assess the effect of each built environment element on PJA under a road pricing policy. To avoid the negative impacts of road charging on PJA, it is anticipated that decision-makers will refer to the results obtained in this study when developing future road pricing schemes.

The next section will discuss the relevant existing literature, while sections three and four provide background on the case study and the research methods. The penultimate section details the results of the study, subdivided into the potential job accessibility analysis, the spatial econometric model, and the cluster analysis. The final chapter presents the conclusions.

\section{Literature review}

\section{- Urban built environment and travel behavior}

Understanding the association between the built environment and travel behavior provides the foundation for exploring how the urban built environment influences the effects of road pricing on PJA. The car-oriented urban sprawl of many modern cities has been criticized for the creation of congestion problems, the release of large amounts of toxic vehicle emissions, and a lack of efficiency in providing infrastructure. In response, the effect of the built environment on travel behavior has been recognized as an important issue in the transportation field. Previous studies have shown that the "three or five Ds" characteristics of the built environment are cumulatively affecting travel behavior alongside socio-economic attributes (Ewing and Cervero, 2010). Normally, other things being equal, travelers in regions with higher levels of density, land use diversity, destination and transit accessibility, and better street design would prefer to drive less than travelers of regions with lower levels of these indicators (Handy et al., 2005; van Wee, 2011).

It is important to note that residential self-selection is an inevitable problem when using actual 
survey data and regression analysis methods to investigate the effect of the built environment on travel behavior (Aditjandra et al., 2012; Cao et al., 2009). Researchers have used various methods to tackle this problem, such as structural equation modelling (SEM) or a quasi-longitudinal SEM approach. They found that the built environment does have an influence on travel behavior, even when excluding the interference of residential self-selection (Aditjandra et al., 2012; Cao et al., 2007). The LUTI model (TRANUS model) is applied in this study to examine the impact of built environment on the PJA effects of road charging. As opposed to the empirical data studies which typically use regression analysis, the TRANUS model applies random utility theory to model location and travel route choice. This method allows the model to eliminate residential self-selection interference.

\section{- Impact of road pricing on job distribution}

From the foregoing analysis, we know that the impact of road pricing on regional PJA is affected by two factors: regional job distribution and travel time (or travel cost) between regions. In view of this, we next discuss the influence of road tolls on regional job distribution. Many studies have been conducted to quantify different aspects of the short term travel behavior effects (such as travel mode, path choice) of road pricing (de Palma and Lindsey, 2011; Tsekeris and Voß, 2009). In recent years, some researchers have begun to focus on the long term effects of road pricing, such as on the impacts of road pricing on the distribution of job and population (Anas and $\mathrm{Xu}$, 1999; McArthur et al., 2012; Tillema et al., 2010a, b; Zhong et al., 2015). The theoretical underpinnings of these studies lie in expected utility theory and discrete choice modeling, assuming that individuals and business enterprises are rational, and make their spatial location decisions according to the principle of expected utility maximization. In theory, after the implementation of a cordon-based road pricing policy, the travel costs of both individual and business enterprise will increase. In order to attract workers, business enterprises need to incur higher operating costs, resulting in some business enterprises, especially those marginal operators, choosing to move out of the charging area (Whitehead, 2002), and ultimately leading to a reduction in the number of jobs within the road pricing area. Based on different regional data, many researchers confirmed that cordon-based road pricing does reduce the number of jobs in the cordon pricing area (Gupta et al., 2006; Still et al., 1999; Tillema et al., 2010a; Zhong et al., 2015). It should be noted that these studies did not analyze how road tolls impact on regional PJA.

\section{- Effect of road pricing on potential job accessibility}

There is a lot of literature on (road) accessibility (Geurs and van Wee, 2004; Karou and Hull, 2014 Keeling, 2009; Páez et al., 2012; Sánchez-Mateos et al., 2014; Zondag et al., 2015) and also specifically on potential job accessibility (Cheng and Bertolini, 2013; Grengs, 2010; Muhammad et al., 2008; Reggiani et al., 2011; Tilahun and Fan, 2014; Zhao and Lu, 2010). However, due to the complexity of the problem, papers dedicated to examining the PJA effects of road charging using pure economic theory, especially focusing on the differing impacts of road pricing on the PJA of regions with different built environments, are very scant. Researchers have focused more on the use of computer simulation to investigate this complex relationship. These studies can be roughly subdivided into two classes: independent model and integrated model approaches. An independent model approach refers to the practice of evaluating the impact of road pricing on accessibility by using land use or transportation models independently or successively without a feedback loop (Condeço-Melhorado et al., 2011; Di Ciommo and Lucas, 2014). It's worth noting that the independent model method has some advantages, including relatively small data requirements, easy calculations, and so on. However, this method does not consider the links between land use and transportation and it may lead to a substantial underestimation in policy effects. The integrated model approach, which refers to the application of the LUTI model to estimate the accessibility effects of road pricing, is a good solution to this problem (Wang et al., 2015).

The road impedance function can be measured in terms of generalized transport costs and travel time. Theoretically, when the road impedance function is measured by generalized transport costs (including road tolls), the implementation of a cordon-based road pricing policy may reduce the PJA within the cordon area. This is due to the fact that cordon pricing may decrease the number of jobs and increase the generalized transport costs, resulting in a reduction in the PJA within the 
road pricing area. The existing literature confirmed this conclusion (Di Ciommo and Lucas, 2014; Wang et al., 2015). For example, using a LUTI model, Wang et al. (2015) found that cordon pricing may decrease the PJA of the road pricing area when the impedance function is measured by travel costs. It should be emphasized that when the impedance function is measured by travel time, the influence of a cordon-based road pricing policy on the PJA is not easy to analyze. This is because, for a road pricing area, cordon pricing may decrease the number of jobs, and make the PJA have a tendency to decrease. However, on the other hand, cordon pricing could reduce traffic congestion and travel time, and improve the PJA within the cordon area. The working direction of these two forces is opposing, making it difficult to determine which factors play a leading role. In order to avoid the negative effects of road pricing, it is necessary to explore the PJA effects of road pricing in depth from the travel time point of view.

In summary, this paper focuses on the effects of road tolls on the PJA. The following characteristics make this paper different from the previous studies:

First of all, except for Wang et al. (2015), most of the existing research usually adopted the independent model approach to study the impact of road pricing on PJA. However, when considering different time scale (short term or long term effects), a road charging scheme will impact regional accessibility differently (Condeço-Melhorado et al., 2011). Besides, the calculation of accessibility indicators requires some consideration of both land use and transportation systems (Levine and Garb, 2002). In view of these facts, an evaluation of the effects of road pricing on PJA should be incorporated into the framework of a LUTI model. For the above reasons, this paper uses the LUTI model TRANUS as an analysis platform.

Secondly, as is widely known within the field, the potential job accessibility of a region is associated with the regional job distribution and the performance of the transportation system, both of which are closely related to the built environment of the region. Built environment factors can include elements such as land use or job distribution, density, diversity, street design, and the service level of the public transportation system. However, there is limited research that quantitatively examines the relationships between the PJA effects of road tolls and the built environment. In fact, establishing this relationship can help us to answer the question of what factors influence the PJA effects of road pricing. In the profession's derived demand framework for transportation, this is very important issue. Understanding these factors will enable us to develop transportation policies that favor high levels of regional PJA and avoid or minimize the negative effects of road charging. Otherwise, if the implementation of road pricing policy leads only to enhanced mobility rather than to enhanced accessibility, then such a policy is doomed to failure (Levine and Garb, 2002). Therefore, as opposed to previous studies, a spatial econometric approach is used in this paper to establish the relationship between the built environment factors and the PJA effects of road pricing.

Finally, the available literature is mainly concerned with the impacts of a road charging policy on the overall regional job distribution and accessibility (Di Ciommo and Lucas, 2014; Gupta et al., 2006; Still et al., 1999). Therefore, the available studies could not distinguish the differences in the PJA effects of road pricing on regions with different built environments. This resulted in the negative effect of road pricing on some sensitive areas being weakened and neglected. By using a cluster analysis technique, this study further explores the differences of the PJA effects of road user charging on regions with different built environments.

\section{The case study of Jiangyin}

\subsection{Regional development scenarios}

The study area for this analysis is the city of Jiangyin, Jiangsu province, located on the Yangtze River in the southeastern China. Jiangyin had a population of 1.6 million inhabitants in 2010, and covers an area of $988 \mathrm{~km}^{2}$. Based on a recently completed comprehensive plan (Jiangsu Institute of Urban Planning and Design, 2011), three alternative regional development scenarios are designed in this study. Table 1 describes the characteristics of each scenario. Projections are carried out every five years from 2010 through 2025. One scenario is the business as usual scenario (which we call "Scenario A"), which describes the development of Jiangyin without any 
additional land use or transportation policies implemented after the year 2010. The other two road pricing scenarios are developed on the basis of Trend Scenario A, as shown in Table 1.

The city of Jiangyin is subdivided into two parts: the downtown road pricing area and the peripheral area, including a total of 265 TAZs. The road pricing region contains 56 TAZs, while the peripheral area consists of 209 TAZs.

\subsection{Road pricing schemes}

This study analyzes cordon tolls, with the specific cordon pricing scheme given as follows:

- Charing area: City center of Jiangyin, as shown in Figure 2.

- Charing object and period: Private cars entering the cordon area during peak hours.

- Charing rates: This paper considers two toll rates. ${ }^{1}$ These are 10 Chinese Yuan (CNY) and $20 \mathrm{CNY}$, respectively. The intent is to explore the effects of toll rates on potential job accessibility.

\subsection{Data sources}

Three main data types are adopted to describe the land use and transportation features of Jiangyin. The first one is the Jiangyin Comprehensive Plan, which provides data on land use type, area, price, population, and the number of jobs in each TAZ. The second data type is traffic supply information provided by the Jiangyin Bureau of Transportation, which describes the road characteristics, such as road names, type, capacity, length, speed limit, and flow at peak hours for the selected roads. The third data type is the public transportation characteristics database from the Jiangyin public transportation company; this data includes operation time, cost, speed, fares, average waiting time, carrying capacity, and average occupancy.

Figure 2 Map of Jiangyin and the toll ring

Table 1 Description of the characteristics of three scenarios

\section{Methodology}

\subsection{The TRANUS model}

TRANUS is an operational LUTI model, which has been widely used in many regions, including Europe, the United States, and China (de la Barra, 1989; Zhong et al., 2015). The theoretical basis of the TRANUS model includes random utility theory, gravity and entropy models, spatial microeconomics, and input-output analysis. An important characteristic of the TRANUS model is the use of the same discrete choice model within a single framework, keeping total theoretical consistency throughout the decision chain (de la Barra et al., 1984).

The Jiangyin integrated model is largely made up of three parts, as shown in Table 2 . The economic and spatial interactions between activities or different land use sectors generate travel demand. The transportation subsystem, on the contrary, assigns travel demand to both physical supply and operative supply, and influences activity location and interaction through accessibility and distance-decay.

Table 2 Components of the Jiangyin integrated model

As discussed before, this paper considers three different development scenarios, namely the Trend

\footnotetext{
${ }^{1}$ The purpose of this paper is to study the long-term impact of road pricing on the potential job accessibility. If we use a dynamic charging strategy, the ordinary static traffic assignment model (for example, TRANUS) is no longer applicable, and the more complex dynamic traffic assignment (DTA) model is needed. The DTA model is time-consuming. More importantly, the DTA model emphasizes the short-term dynamic effects, which is not consistent with our research objectives. Therefore, we use a flat road pricing policy instead of a dynamic road pricing policy in this paper.
} 
Scenario A, 10 CNY cordon toll Scenario C10, and 20 CNY cordon toll Scenario C20. The base year of the Jiangyin integrated model is 2010. Simulations are carried out every five years from 2010 through 2025, considering the above three development scenarios. The cordon toll policy is to be implemented in 2020. Recognizing that transportation impacts on land use require a certain amount of time (Tillema et al., 2010a; Whitehead, 2005; Zhong et al., 2015), this study applies the simulation results in 2025 to estimate the impacts of road charging on potential job accessibility (PJA). In other words, this paper uses 2020 urban built environment data as the independent variables and uses the number of jobs and network travel time in 2025 to calculate the potential job accessibility indicator. It is also worth pointing out that jobs in Jiangyin are mainly distributed in the industrial, retail, and government sectors. Thus, this study uses the jobs in these three sectors to calculate the PJA indicator.

Model calibration is as important as model structure in providing reliable forecasts of land use and transportation changes. Using survey data in 2010 and a piece-wise estimation approach (Abraham and Hunt, 2000), a full calibration was conducted for the TRANUS model of Jiangyin as part of this analysis. For more details on model calibration for the Jiangyin integrated model, please see Zhong et al. (2015).

\subsection{Potential job accessibility indicator}

This study explores the associations between the built environment and the potential job accessibility effects of road pricing. With this in mind, the broadly used potential accessibility indicator is adopted in this study to evaluate the aggregate level of job accessibility (Geurs and van Wee, 2004; Wang et al., 2015). This indicator is comprised of two parts, a weighted variable describing the number of jobs located in a specific zone and a travel cost variable measuring the cost of traveling between the specific zone and other employment zones (Páez, 2004). In general, connectivity to a large number of jobs will increase the PJA of a region. A lack of connectivity to many jobs, on the other hand, will decrease the PJA. The PJA, in this study, is given by the following function:

$$
P J A_{i}=\sum_{j} J_{j} * F\left(t_{i j}\right)
$$

where $P J A_{i}$ indicates the PJA for zone $i, J_{j}$ represents the number of jobs located in zone $j, F\left(t_{i j}\right)$ refers to an impedance function, $t_{i j}$ means the minimum travel time between each OD pair. In this study, $F\left(t_{i j}\right)$ is given by the following function:

$$
F\left(t_{i j}\right)=\varpi^{*} \exp \left[\theta+\mu^{*} t_{i j}\right]
$$

where $\varpi, \theta, \mu$ are the empirically derived impedance parameters, and in this paper $\varpi=0.001, \theta=-0.4, \mu=-0.15$ (Cervero and Kockelman, 1997).

In order to calculate the PJA of each TAZ, travel time $t_{i j}$, which indicates the minimum travel time between two zones, is determined by the TRANUS model based on the optimum combination of transportation modes. The distribution of jobs in each of the scenarios will be calculated using the TRANUS model as well.

\subsection{Extraction of the basic factors of the built environment}

Taking into account the purpose of this study and the data availability, a total of five major categories and twenty raw variables are adopted to measure various aspects of the built environment. Summary statistics for all these measures in the 265 TAZs are given in Table $3 .^{2}$ It

${ }^{2}$ In order to facilitate the calculation, we use Euclidean distances to measure the distance from a region to an element of infrastructure, on the premise that the general results are not affected. On the other hand, in order to ensure the accuracy of the results, we use street distances to calculate the minimum travel time between different regions. In Table 3, the 'population density' refers to the average number of people per unit area, while the 'population' refers to the average number of people per TAZ. 
should be pointed out that some of the raw variables of the built environment are highly correlated. For example, the 'street density' variable is highly correlated with the 'length of street' variable. In order to use sets of variables to describe the essential elements of various built environments and to allow for colinearity, factor analysis was adopted, as recommended by Cervero and Kockelman (1997). The most important objective of factor analysis methodology is data reduction and summarization (Child, 2006). In this paper, for example, it allowed variables like 'number of intersections', 'length of street', and 'street density' to be linearly combined to describe the element of 'street design'.

A total of seven essential elements (factors) is extracted from the twenty raw variables for all 265 TAZs, including distance to the central business district (CBD), population, retail job condition, industrial job condition, government job condition, street design and conventional bus condition, and distance to infrastructure (see Table 6, does not include the 'within the road pricing region' variable). ${ }^{3}$ These results will serve as the basic input data required by the spatial econometric model of potential job accessibility in Section 4.4. Similarly, seven essential factors are also abstracted for the 56 road pricing TAZs and the 209 non-tolled TAZs, respectively (see Table 4 and 5 in Section 4.5). These essential factors are then used in the cluster analysis step in Section 4.5 .

Table 3 Summary statistics for all raw measures of built environment

\subsection{Spatial econometric model of potential job accessibility}

The impacts of road pricing policy on potential job accessibility are strongly affected by spatial effects. This is because both of the components of PJA, namely the number of jobs and the travel time between different regions have been shown to have significant spatial effects (Anselin and Bera, 1998; LeSage and Pace, 2009). The spatial effect implies spatial autocorrelation, spatial heterogeneity, or both. Spatial autocorrelation means that the values observed at one location depend on the values of nearby locations, whereas spatial heterogeneity refers to the spatial correlation of the error terms (LeSage and Pace, 2009).

The spatial econometric approach is employed in this study to capture the spatial effects of road pricing on PJA (Anselin and Bera, 1998; LeSage and Pace, 2009). Both global and local spatial autocorrelation analyses are conducted based on global and local Moran's I statistics. Additionally, the Lagrange Multiplier test is also used to test for the existence of spatial effects. Test results confirm the presence of spatial autocorrelation in the impacts of road pricing on PJA in our dataset. In other words, in this study, the PJA (dependent variable) of a region depends not only on the region's own characteristics (independent variables), but also on the PJA of neighboring regions. Therefore, using a spatial lag model (SLM), this study establishes the relationships between (built environment) explanatory variables and regional PJA under a road charging policy (Anselin and Bera, 1998). The proposed SLM is estimated using the maximum likelihood estimation and implemented in the spatial econometric software package GeoDa (Anselin et al., 2006). The spatial weight matrix for the study contains 265 TAZs and was created by identifying the distance-based contiguity based on the centroids of all TAZs in 2010. Eqn. (3) presents the general form of the SLM applied in this paper:

$$
P=\omega+\phi W P+\tau E+\varepsilon
$$

\footnotetext{
${ }^{3}$ We take Table 6 as an example to explain what variables are included in each of the seven essential factors in Table 6. The factor 'distance to the central business district (CBD)' contains 'regional size' and 'distance to central business district'; the factor 'population' contains 'population density', 'population', and 'residential size'; the factor 'retail job condition' contains 'retail jobs density', 'number of retail jobs', and 'retail size'; the factor 'industrial job condition' contains 'industrial jobs density', 'number of industrial jobs', and 'industrial size'; The factor 'government job condition' contains 'government jobs density' and 'number of government jobs'; the factor 'street design and conventional bus condition' contains 'number of intersections', 'length of street', 'density of street', and 'number of bus stations'; the factor 'distance to infrastructure' contains 'distance to commercial centers', 'distance to school', and 'distance to hospital'.
} 
where $P$ represents the PJA, $\omega$ is the constant term, $\phi$ is the coefficient of the spatial autocorrelation, $W$ is the spatial weights matrix, $W P$ represents the effects of neighboring PJA (spatial lag terms), $\tau$ is the regression coefficient, $E$ is the explanatory variables, and $\varepsilon$ is the error terms.

\subsection{Distinguishing the effects of road charging on potential job accessibility}

This study, as mentioned before, uses TAZs as the basic analysis unit. It should be noted that the PJA effects of road pricing on each TAZ are not only associated with the road pricing scheme, but also closely related to the built environment elements of that TAZ. In general, the conventional delineation method could not differentiate TAZs by their built environment characteristics. The methods used in this analysis, however, do allow for differentiation based on built environment characteristics. With the purpose of assessing the differences of the PJA effects of road user charging on TAZs with different built environment attributes and further explaining the results obtained by the spatial econometric model, the TAZs, which are located inside and outside the road pricing area, need to be reclassified according to their own built environment attributes. A K-means cluster analysis is used in this study to quantitatively classify TAZs into different TAZ types, based on the calculated scores (Bartlett estimation method) of each TAZ on the seven essential elements identified for the tolled and non-tolled TAZs in Section 4.3. The K-means procedure is designed to minimize the internal variability of each TAZ type, while maximizing the external dissimilarities to other TAZ types.

\section{- Results of cluster analysis of TAZs within the road pricing region}

This study identifies the best clustering solution based on the following principles: the classification results can be interpreted easily and the numbers of TAZ types are minimized in the premise of ensuring diversity. A series of analyses were performed, varying the number of clusters produced ( 3 to 10). Considering the above principles, this paper found that the best clustering solution is eight clusters of TAZs within the road pricing region. Table 4 provides the cluster centroid values of the eight TAZ types. The last two rows of Table 4 represent the distribution of TAZs by each TAZ type. For example, there are 15 TAZs that belong to TAZ type 6 . The values of a cluster centroid describe a series of attributes of a particular TAZ type, which reveal how a TAZ type differs from other TAZ types according to the seven essential elements discussed earlier: regional size, industrial job condition, retail job and conventional bus condition, population, government job condition, street design, and infrastructure accessibility. For example, TAZ type 5 has a large number of industrial jobs and retail jobs. Additionally, TAZs in this group have a good conventional bus condition.

Table 4 The values of the cluster centroids of eight TAZ types within the road pricing region

- Results of cluster analysis of TAZs outside the road pricing area

After examining the outcomes with varying numbers of clusters, this analysis ultimately found that eight clusters best captures the diversity in the major features of the built environment attributes within the TAZs outside the pricing region (see Table 5). Likewise, the centroid values of each TAZ type reveal how TAZ types differ from other TAZ types according to the seven essential elements: CBD accessibility, retail job condition, industrial job condition, population, street design and conventional bus condition, government job condition, and infrastructure accessibility. Take TAZ type 4 for instance, this cluster has the largest number of industrial jobs and the best street design and bus conditions. TAZs within this cluster are far away from the CBD. However, they have good infrastructure accessibility.

Table 5 The values of the cluster centroids of eight TAZ types outside the road pricing area 


\section{Analysis of Results}

\subsection{Potential job accessibility analysis}

\subsubsection{Combined effects of both travel time and job redistribution}

The changes in potential job accessibility (PJA) when charging $20 \mathrm{CNY}$ road pricing (changes in the PJA indicators between Scenario 25C20 and 25A) is shown in Figure 3. The term "25C20" indicates a $20 \mathrm{CNY}$ cordon toll scenario in 2025. The term "25A" refers to the business as usual scenario in 2025. In this case, the change of PJA is due to the combined effects of changes in both travel time and job redistribution. From Figure 3, we can see that when we consider the combined effects of both travel time and job redistribution, road pricing will not only greatly enhance the PJA of the regions within the charging area, but will also observably reduce the PJA of the regions close to the toll ring or the $\mathrm{CBD}$, but outside the road pricing area. This phenomenon can be reasonably explained by boundary effects (Banister, 2003). To avoid paying road tolls, travelers will not travel across the charging area, but rather will travel around the downtown, possibly resulting in congestion and a reduction in the PJA of these regions.

Figure 3 Changes of potential job accessibility when charging 20 CNY road toll (25C20-25A)

\subsubsection{Independent effects of travel time and job redistribution}

Figure 4 depicts the changes in PJA between the fixed job distribution scenario and Scenario $25 \mathrm{~A}$. To calculate the PJA in the fixed job distribution scenario, we use the distribution of jobs from Scenario 25A, which represents a fixed job distribution status. The travel time used in this scenario is taken from Scenario 25C20. By using these baseline conditions, this scenario will represent the independent effect of travel time on the PJA. From Figure 4, we can observe that when we only consider the travel time effect (fixed job distribution), the changes of PJA are similar to Figure 3 with the exception of the south and northwest regions. This indicates that compared with the job redistribution effects, the change in travel time has a greater influence on the PJA. One possible reason why we can only observe changes in the south and northwest regions is that the downtown area (within the toll cordon) has the highest PJA. Therefore, the change of PJA caused by the job redistribution could not be reflected in Figure 4. On the contrary, as the PJA of the peripheral region is relatively low, a slight change in job distribution will be reflected in the PJA index, as shown in the lower part of Figure 4.

Figure 5 shows the changes in PJA between the fixed travel time scenario and Scenario 25A. In order to reflect the independent impact of job distribution on the PJA, we adopt the travel time from Scenario 25A and the job distribution from Scenario 25C20 to calculate the PJA of the fixed travel time scenario. From Figure 5 we can see that, when the travel time effect is fixed, the PJA of the road pricing area decreased slightly, while the PJA of the peripheral region increased mildly. This may be due to the fact that cordon-based road pricing may disperse centrally distributed jobs outside the road pricing (downtown) area (Zhong et al., 2015). As a result, when the travel time is constant, road pricing will increase the PJA of the suburban area, but decrease the PJA of the downtown area.

In summary, after the launch of road user charges, this analysis found that travel time change has a greater impact than the job redistribution on the PJA. However, this does not mean that the effect of job redistribution is not important. It just shows that, under the current road pricing scheme, the effect of job redistribution on the PJA is lower than the effect of travel time change.

Figure 4 Changes of potential job accessibility when the job distribution is fixed

Figure 5 Changes of potential job accessibility when travel time is fixed

\subsection{Results of the spatial econometric model}

Table 6 provides the relationships between the potential job accessibility (and its changes, namely the PJA under Scenario C minus the PJA under Scenarios A) and the built environment variables under $10 \mathrm{CNY}$ and $20 \mathrm{CNY}$ road pricing schemes (Scenario C10 and C20) in 2025. From the relationships between the PJA and the built environment variables (the second and third columns 
of Table 6), we can observe that:

- The spatial autocorrelation coefficient phi is significant in all scenarios, which illustrates the importance of considering the spatial effects and PJA interdependencies. The positive sign of the phi in $\mathrm{C} 10$ and $\mathrm{C} 20$ is as expected. If a region has a high level of PJA, its neighbors are more likely to have high PJA.

- Overall, most of the explanatory variables are highly significant at the 0.001 and 0.005 levels, except 'population' and 'distance to infrastructure'. The PJA of a region is positively related to the distribution of jobs within that region. Furthermore, The PJA of a region is also associated with the 'street design' and 'conventional bus condition', both of which also have a positive impact on the regional PJA.

- The coefficient of 'within the road pricing region' is positive, while the coefficient of 'distance to CBD' is negative. The results indicate that, from the perspective of travel time, the PJA of regions within the road pricing area are significantly higher than that of the region outside the road pricing area. In addition, the further from the CBD, the lower the PJA.

Exploring the relationships between the PJA changes and the built environment variables (the last two columns of Table 6), the following observations can be drawn:

- The negative sign of phi (the coefficient of the spatial autocorrelation) in C10-A and C20-A means that an increase in the PJA of a region may be accompanied by a decrease in the PJA of the surrounding regions after the introduction of a road pricing policy. This may be because road pricing will lead to the redistribution of both jobs and traffic congestion (Anas and Xu, 1999; McArthur et al., 2012; Still et al., 1999; Tillema et al., 2010a; Zhong et al., 2015), which will cause a shift of the PJA between regions.

- It's interesting to note that when we focus on the PJA changes caused by a road pricing policy, the coefficient of the 'within the road pricing region' variable is still positive. However, in this situation, the coefficient of 'distance to CBD' also becomes positive. This shows that road pricing still has a positive effect on the PJA changes of the regions located inside the toll ring. Once beyond the road pricing area, especially the regions close around the toll ring (regions close to the toll ring or the $\mathrm{CBD}$, but outside the road pricing area), the PJA changes increase markedly with distance from the CBD after the introduction of road pricing. This can also be seen in Figure 3.

- Finally, the coefficient of 'government job' is negative. This paper will further explore why the 'government job' variable is negatively related to the changes in PJA following the implementation of a road charging policy by using a cluster analysis approach in Section 5.3.

Table 6 Regression results for potential job accessibility and its changes under different toll level

\subsection{Results of the cluster analysis}

To interpret the regression outcomes obtained in Section 5.2, we next differentiate the PJA effects of road charging according to the classification of TAZs and determine the associations between these differences and the built environment elements. In order to distinguish between the spatial effects of road pricing, the road pricing zones and the non-tolled zones are discussed separately.

Table 7 shows the differences in the PJA indicators of different types of TAZs within the charging area between Scenarios A and C. Figure 6 is generated based on Table 4. Combining the information provided in Figure 6 and Table 7, we can see that:

- Generally, the PJA indicators of all the TAZ types within the cordon area increased after the implementation of road pricing, and the PJA indicators noticeably increased with the increase of the road charging level. In addition, the PJA changes (C10-A and C20-A) of these TAZs are highly associated with the number of industrial and retail jobs, the bus condition, street design, and distance to infrastructure.

- Specifically, in the regions with a large number of industrial and retail jobs, better public 
transportation conditions, and which are close to infrastructure, the PJA indicator increased the most after the implementation of road pricing, such as in TAZ type 5. One explanation is that due to the good traffic and infrastructure conditions, compared with other types of TAZs, the number of jobs of this type of TAZ group increased the most after the implementation of a road pricing policy (Zhong et al., 2015). As a result of this growth in the number of jobs, the PJA of these regions also increased the most.

- TAZ type 3 has a small number of industrial jobs, but the street design, retail job, and bus conditions within these TAZs are very good, and these TAZs have good infrastructure accessibility. Under these conditions, the PJA indicator was also noticeably improved. On the other hand, TAZ type 7 has the largest number of industrial jobs and the retail job and bus conditions are the worst, all of which lead to a relatively small increase in the PJA indicator.

- There is a small increase in the PJA indicator of TAZ type 8. One plausible explanation is that although TAZ type 8 has the best retail job and bus conditions, the street design and government job of these TAZs are particularly bad. The PJA indicator of TAZ type 1 is the worst in all TAZ types. This is because though the TAZ type 1 is the administrative center of the city, all of the other built environment attributes of this cluster are not ideal.

Figure 6 Classification results of the TAZs within the road pricing area

Table 7 Change in the PJA indicators of different TAZ types within the cordon between Scenarios A and C

The differences in the PJA indicators of different TAZ types outside the road charging area between Scenarios A and C are described in Table 8. Figure 7 is produced according to Table 5. The results in Figure 7 and Table 8 show that:

- Overall, the PJA indicators of the TAZs outside the cordon area are also closely related to the number of jobs, street design and bus conditions. However, different from the TAZs inside the cordon, except for TAZ types 1, 4, and 5, the PJA indicators decreased significantly along with the increase of the road pricing level.

- TAZ type 1 has the largest number of retail jobs, and the street design and public transit conditions are not bad. The PJA indicator of TAZ type 1 increased the most out of all of the TAZ types. One possible reason is that, to avoid paying road tolls, residents who originally preferred to shop in the road pricing area but live outside the cordon are now more inclined to shop outside the cordon. Thus, the number of retail jobs of these regions would increase after the introduction of road pricing, resulting in an increase in the PJA of these regions.

- Both TAZ types 4 and 7 have a large number of industrial jobs. However, the changes in the PJA between the two TAZ types are quite different after the increase of the toll level. This indicates that the industrial job variable is only a factor and PJA is also related to other elements of the built environment of a region, such as street design and bus condition.

- TAZ type 5 represents the employment center, which has a large number of industrial jobs, retail jobs, and government jobs. The PJA indicator for this cluster also increased along with the toll level. Nevertheless, due to the low-grade street design and bus condition, the cost of traveling between this type of TAZ and other employment zones is very high. Therefore, the PJA indicator growth is not notable.

- We observe a large decrease in the PJA indicators of both TAZ types 2 and 6 , following the implementation of road charging. These TAZs are all located close to the toll ring, but outside the cordon pricing area. Due to boundary effects, the roads in these TAZs are generally more crowded, leading to a reduction in the PJA of these regions. Beyond that, though TAZ type 6 has the highest government job density, all of the TAZs belonging to this TAZ groups are lacking in industrial and retail jobs. This explains why the coefficient of "government job", which is obtained from the spatial econometric model, is negative (see Table 6).

Figure 7 Classification results of the TAZs outside the road charging area

Table 8 Change in the PJA indicators of different TAZ types outside the cordon between Scenarios A and C 


\section{Conclusions}

The existing studies explored the impacts of a road charging policy on the overall regional (job) accessibility of a specific region. However, these studies didn't answer what factors influence the potential (job) accessibility (PJA) effects of road pricing. Without examining these PJA effects, these studies have regional limitations and the results often vary depending on the specific road pricing scheme, socioeconomic levels and the built environment of the region. Recognizing this problem, this paper focuses on the elements that influence the PJA effects of road pricing. This is critical in developing a transportation policy that supports high regional PJA. In addition, understanding these factors will enable governments to avoid or minimize the negative effects of road charging on PJA. In this paper, a quantitative method, which combines the TRANUS model with a spatial econometric approach, was adopted to analyze the impacts of the built environment on the PJA effects of road charging. Additionally, with the intention of further exploring the differences in the PJA effects of road charging on traffic analysis zones (TAZs) with different combinations of built environment elements, a method combining factor and cluster analysis was employed to assorted TAZ types.

The most prominent practical aspects of this paper are provided as follows:

First, though previous studies found that road pricing policy does influence the (re)distribution of regional jobs (Gupta et al., 2006; Still et al., 1999; Tillema et al., 2010a; Zhong et al., 2015), there is a lack of research on the influence factors of the PJA effects of road pricing. This paper found that the influence of road pricing on PJA is closely related to the built environment of the region. Establishing the relationship between the built environment and the PJA effects of road pricing can help us to understand the influencing factors of the PJA effects of road pricing. In particular, under a road pricing policy, we found that measures of industrial jobs, retail jobs, government jobs, street design and bus condition are positively related to PJA, while distance to the central business district (CBD) is negatively related. More specifically, being within the road pricing region is also positively related to PJA, indicating that from the perspective of travel time, the PJA of regions within the pricing cordon are higher than that of the region outside the cordon. Decision-makers should be aware of the impacts of these built environment factors on the PJA when designing a road charging scheme.

Secondly, previous studies found that the application of a cordon-based road pricing policy may reduce the PJA within the cordon area when the impedance function is measured by travel costs (Di Ciommo and Lucas, 2014; Wang et al., 2015). Our results further pointed out that cordon pricing could increase the PJA of the road pricing area when the impedance function is measured by travel time. More importantly, we found that though road pricing will enhance the PJA of the regions within the cordon, it will also reduce the PJA of the regions close to the toll ring or the CBD, but outside the road pricing area. This result also confirms the boundary effects of road pricing proposed by previous study (Banister, 2003). In order to reduce the negative effect of road pricing on regions around the cordon, this result suggests that governments should conduct an in-depth analysis of these regions before implementing a road pricing policy. For example, we can improve the PJA of these sensitive regions by using measures such as time varying road pricing, hierarchical charging areas, park and ride lots, land use planning, and public transportation.

Thirdly, the results in this paper confirm that the impacts of road pricing policy on PJA are strongly affected by spatial effects. More concretely, the PJA effects of road pricing are strongly affected by the PJA of neighboring regions. The spatial econometric approach is adopted in this paper to capture the spatial effects of road pricing on PJA. With the aid of a spatial econometric model, we can obtain some new valuable information for policy making. The main finding is that the spatial effects of road pricing on PJA and PJA changes are totally different. In exploring the relationship between the PJA and the road pricing, we found that the spatial autocorrelation coefficient is positive. This means that the periphery of the high PJA regions also has high PJA, which is consistent with the existing research and knowledge (Wang et al., 2015). However, when we explore the relationship between the PJA changes and the road pricing policy, one interesting finding is that the spatial autocorrelation coefficient is negative. This finding indicates that an increase in the PJA of a region may be accompanied by a decrease in the PJA of the surrounding regions after the introduction of a road pricing policy. This may be because road pricing will cause 
the redistribution of both jobs and traffic congestion (Anas and Xu, 1999; Tillema et al., 2010a; Zhong et al., 2015). Therefore, the PJA between regions will be reallocated. The practical implication of this phenomenon is that through road pricing, we will not be able to increase the PJA of all regions, but rather will affect a (re)distribution of PJA between different regions. This policy implication is important, and invites concern for nearby regions that may be negatively affected by a road pricing policy.

Finally, the existing literature only analyzed the impacts of a road pricing policy on the overall regional job distribution and accessibility, reflecting the effects of road pricing in an average sense (Di Ciommo and Lucas, 2014; Gupta et al., 2006; Still et al., 1999). As a result, these studies could not distinguish the differences in the PJA effects of road pricing on different regions, and the negative impact of a road pricing policy on some sensitive areas is often weakened and neglected. Although some studies have demonstrated the spatial differences of the PJA effects of road pricing (Condeço-Melhorado et al., 2011; Wang et al., 2015), there is no in-depth analysis of the reasons for such differences. Our results show that the impacts of road pricing on PJA are the common result of various characteristics of the built environment. Specifically, the higher the number of jobs, the better the public transportation conditions, and the better the street design (high densities of streets and intersections), the less the region will be adversely affected by a road charging policy, and vice versa. For those TAZ types with a large number of jobs but bad street design and bus conditions, the regional PJA is more likely to be less improved by a road pricing policy. Therefore, to avoid the negative effects of road pricing on PJA, we recommend that the public transportation and street design of the road pricing policy sensitive areas be improved prior to the implementation of such policy, especially the toll ring periphery area.

\section{Acknowledgment}

This research has been supported by National Science Foundation of China (Project No. 51478085), China Postdoctoral Science Foundation (Project No. 2016M601313), the Specialized Research Fund for the Doctoral Program of Higher Education (Project No. 20120041120006), the Fundamental Research Funds for the Central Universities of China (Project No. DUT16RW208), and the Natural Science Foundation of Liaoning Province (Project No. 201602187). We would like to thank the two anonymous reviewers for providing helpful and insightful comments.

\section{Reference}

Abraham, J.E., Hunt, J.D., 2000. Parameter estimation strategies for large-scale urban models. Transportation Research Record: Journal of the Transportation Research Board 1722(1), 9-16.

Aditjandra, P.T., Cao, X., Mulley, C., 2012. Understanding neighbourhood design impact on travel behaviour: An application of structural equations model to a British metropolitan data. Transportation Research Part A: Policy and Practice 46(1), 22-32.

Anas, A., Xu, R., 1999. Congestion, land use, and job dispersion: A general equilibrium model. Journal of Urban Economics 45(3), 451-473.

Anselin, L., Bera, A.K., 1998. Spatial dependence in linear regression models with an introduction to spatial econometrics, In: Ullah, A., Giles, D.E. (Eds.), Handbook of Applied Economic Statistics. Marcel Dekker, New York, NY, pp. 237-289.

Anselin, L., Syabri, I., Kho, Y., 2006. GeoDa: An introduction to spatial data analysis. Geographical Analysis 38(1), $5-22$.

Banister, D., 2003. Critical pragmatism and congestion charging in London. International Social Science Journal 55(176), 249-264.

Cao, X., Mokhtarian, P.L., Handy, S., 2007. Do changes in neighborhood characteristics lead to changes in travel behavior? A structural equations modeling approach. Transportation 34(5), 535-556.

Cao, X., Mokhtarian, P.L., Handy, S.L., 2009. The relationship between the built environment and nonwork travel: A case study of Northern California. Transportation Research Part A: Policy and Practice 43(5), 548-559.

Cervero, R., Kockelman, K., 1997. Travel demand and the 3Ds: Density, diversity, and design. Transportation Research Part D: Transport and Environment 2(3), 199-219.

Cheng, J., Bertolini, L., 2013. Measuring urban job accessibility with distance decay, competition and diversity. Journal of Transport Geography 30, 100-109.

Child, D., 2006. Essentials of factor analysis (3rd ed.). Continuum International, New York. 
Condeço-Melhorado, A., Gutiérrez, J., García-Palomares, J.C., 2011. Spatial impacts of road pricing: Accessibility, regional spillovers and territorial cohesion. Transportation Research Part A: Policy and Practice 45(3), 185-203.

Dalvi, M.Q., Martin, K.M., 1976. The measurement of accessibility: Some preliminary results. Transportation 5(1), $17-42$.

de la Barra, T., 1989. Integrated Land Use and Transport Modelling: Decision chains and hierarchies. Cambridge University Press.

de la Barra, T., Pérez, B., Vera, N., 1984. TRANUS-J: Putting large models into small computers. Environment and Planning B: Planning and Design 11(1), 87-101.

de Palma, A., Lindsey, R., 2011. Traffic congestion pricing methodologies and technologies. Transportation Research Part C: Emerging Technologies 19(6), 1377-1399.

Di Ciommo, F., Lucas, K., 2014. Evaluating the equity effects of road-pricing in the European urban context - The Madrid Metropolitan Area. Applied Geography 54, 74-82.

Ewing, R., Cervero, R., 2010. Travel and the built environment: A meta-analysis. Journal of the American Planning Association 76(3), 265-294.

Geurs, K.T., van Wee, B., 2004. Accessibility evaluation of land-use and transport strategies: Review and research directions. Journal of Transport Geography 12(2), 127-140.

Grengs, J., 2010. Job accessibility and the modal mismatch in Detroit. Journal of Transport Geography 18(1), $42-54$.

Gupta, S., Kalmanje, S., Kockelman, K. M., 2006. Road pricing simulations: traffic, land use and welfare impacts for Austin, Texas. Transportation Planning and Technology, 29(1), 1-23.

Jiangsu Institute of Urban Planning and Design. (2011) The comprehensive planning of Jiangyin (2011-2030). <http://www.jiangyin.gov.cn:88/websites/_ext/wzjq/xxgk/detail_xxgk.jsp?id=1nubkqnyldra0> (06.09.12).

Handy, S., Cao, X., Mokhtarian, P., 2005. Correlation or causality between the built environment and travel behavior? Evidence from Northern California. Transportation Research Part D: Transport and Environment 10(6), 427-444.

Karou, S., Hull, A., 2014. Accessibility modelling: Predicting the impact of planned transport infrastructure on accessibility patterns in Edinburgh, UK. Journal of Transport Geography 35, 1-11.

Keeling, D.J., 2009. Transportation geography: local challenges, global contexts. Progress in Human Geography 33(4), 516-526.

LeSage, J., Pace, R.K., 2009. Introduction to Spatial Econometrics. CRC Press.

Levine, J., Garb, Y., 2002. Congestion pricing's conditional promise: Promotion of accessibility or mobility? Transport Policy 9(3), 179-188.

McArthur, D.P., Thorsen, I., Ubøe, J., 2012. Labour market effects in assessing the costs and benefits of road pricing. Transportation Research Part A: Policy and Practice 46(2), 310-321.

Muhammad, S., de Jong, T., Ottens, H.F.L., 2008. Job accessibility under the influence of information and communication technologies, in the Netherlands. Journal of Transport Geography 16(3), 203-216.

Páez, A., 2004. Network accessibility and the spatial distribution of economic activity in eastern Asia. Urban Studies 41(11), 2211-2230.

Páez, A., Scott, D.M., Morency, C., 2012. Measuring accessibility: Positive and normative implementations of various accessibility indicators. Journal of Transport Geography 25, 141-153.

Reggiani, A., Bucci, P., Russo, G., Haas, A., Nijkamp, P., 2011. Regional labour markets and job accessibility in City Network systems in Germany. Journal of Transport Geography 19(4), 528-536.

Sánchez-Mateos, H.S.M., Sanz, I.M., Francés, J.M.U., Trapero, E.S., 2014. Road accessibility and articulation of metropolitan spatial structures: The case of Madrid (Spain). Journal of Transport Geography 37, 61-73.

Still, B. G., May, A. D., Bristow, A. L, 1999. The assessment of transport impacts on land use: Practical uses in strategic planning. Transport Policy, 6(2), 83-98.

Tilahun, N., Fan, Y., 2014. Transit and job accessibility: An empirical study of access to competitive clusters and regional growth strategies for enhancing transit accessibility. Transport Policy 33, 17-25.

Tillema, T., van Wee, B., Ettema, D., 2010a. The influence of (toll-related) travel costs in residential location decisions of households: A stated choice approach. Transportation Research Part A: Policy and Practice 44(10), 785-796.

Tillema, T., van Wee, B., Ettema, D., 2010b. Road Pricing and Relocation Decisions of Dutch Households. Urban Studies 47(14), 3013-3033.

Tsekeris, T., Voß, S., 2009. Design and evaluation of road pricing: State-of-the-art and methodological advances. Netnomics 10(1), 5-52.

van Wee, B., 2011. Evaluating the impact of land use on travel behaviour: The environment versus accessibility. Journal of Transport Geography 19(6), 1530-1533.

Wang, Y., Monzon, A., Di Ciommo, F., 2015. Assessing the accessibility impact of transport policy by a land-use 
and transport interaction model - The case of Madrid. Computers, Environment and Urban Systems 49, 126-135.

Whitehead, T., 2002. Road user charging and business performance: Identifying the processes of economic change. Transport Policy 9(3), 221-240.

Whitehead, T., 2005. Transport charging interventions and economic activity. Transport Policy 12(5), 451-463.

Zhao, P., Lu, B., 2010. Exploring job accessibility in the transformation context: An institutionalist approach and its application in Beijing. Journal of Transport Geography 18(3), 393-401.

Zhong, S., Wang, S., Jiang, Y., Yu, B., Zhang, W., 2015. Distinguishing the land use effects of road pricing based on the urban form attributes. Transportation Research Part A: Policy and Practice 74, 44-58.

Zhong, S., Xiao, X., Bushell, M., \& Sun, H., 2017. Optimal Road Congestion Pricing for Both Traffic Efficiency and Safety under Demand Uncertainty. Journal of Transportation Engineering, Part A: Systems. (In Press)

Zondag, B., de Bok, M., Geurs, K.T., Molenwijk, E., 2015. Accessibility modeling and evaluation: The TIGRIS XL land-use and transport interaction model for the Netherlands. Computers, Environment and Urban Systems 49, 115-125. 
Input: Regional development scenario, land use, physical transport network data

Output: Potential job accessibility (PJA), land use area, population, job, traffic flow, travel time

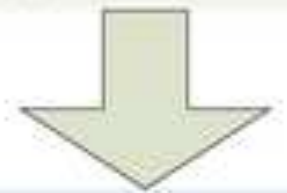

Input: Built environment data

Output: Essential elements of built environment



Input: Essential elements of built environment, PJA

Output: Spatial lag model (SLM) for PJA, traffic analysis zone types
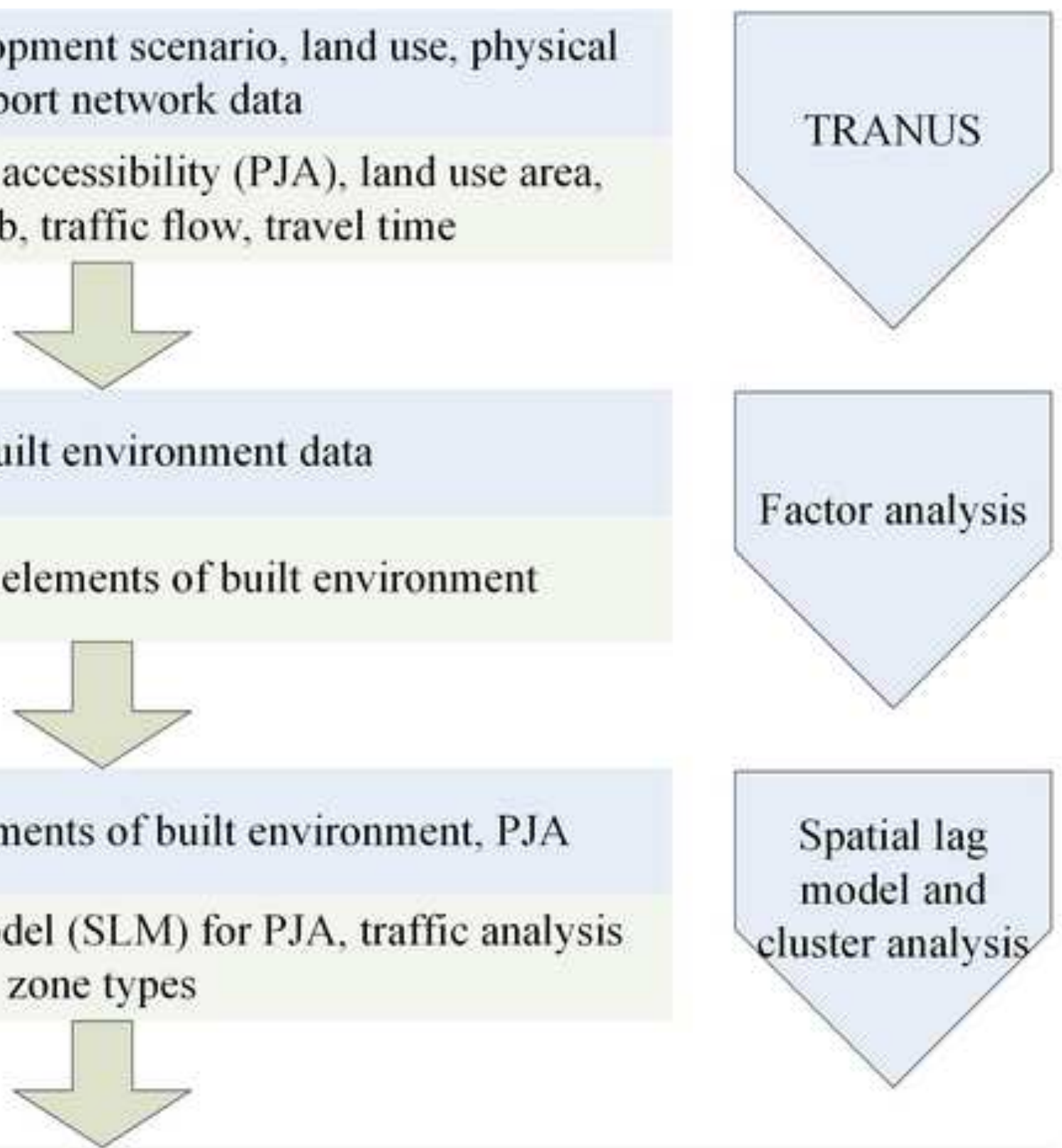

Factor analysis

Spatial lag model and cluster analysis

Understanding and distinguishing the impacts of road pricing on potential job accessibility 


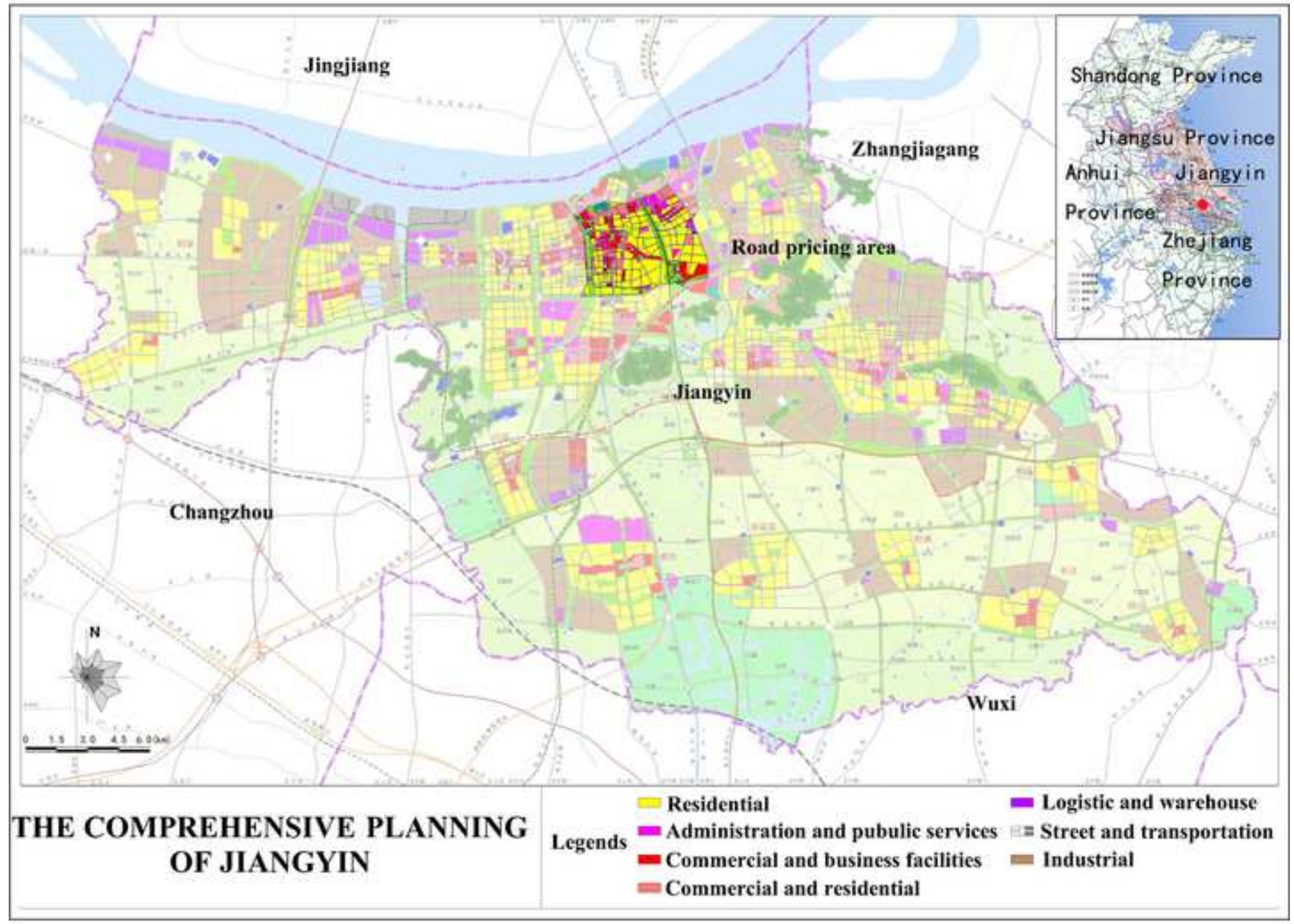




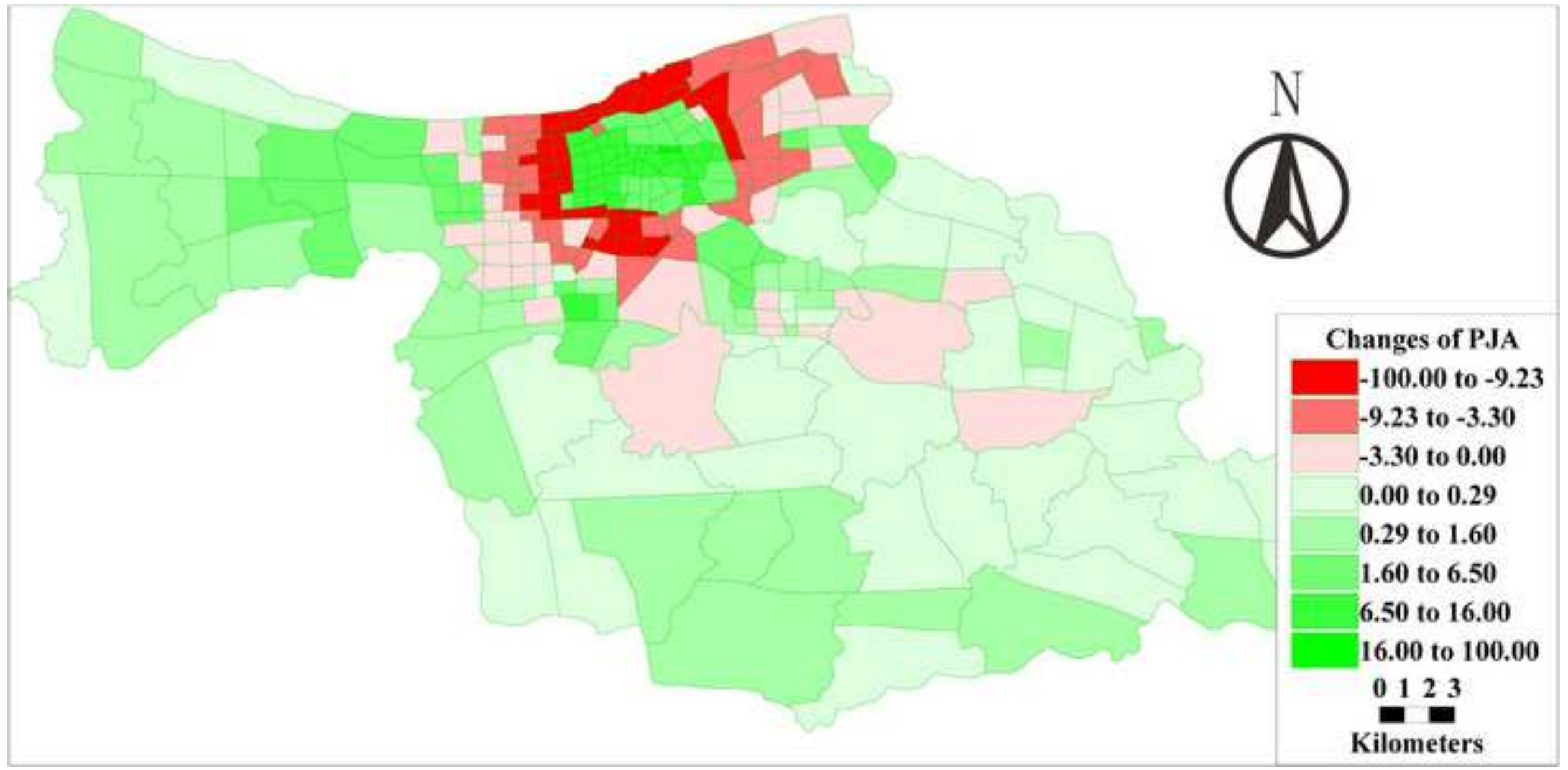




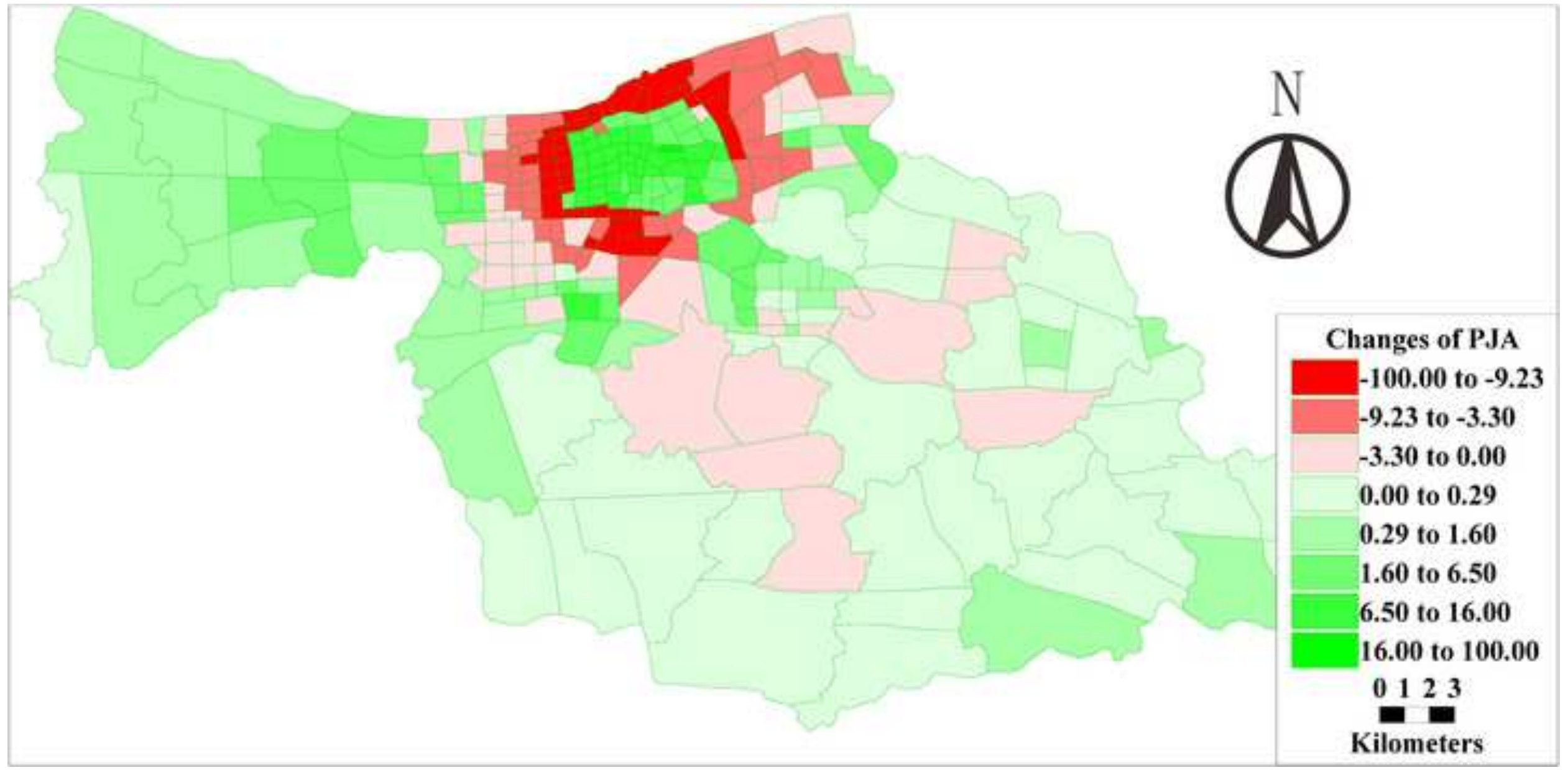




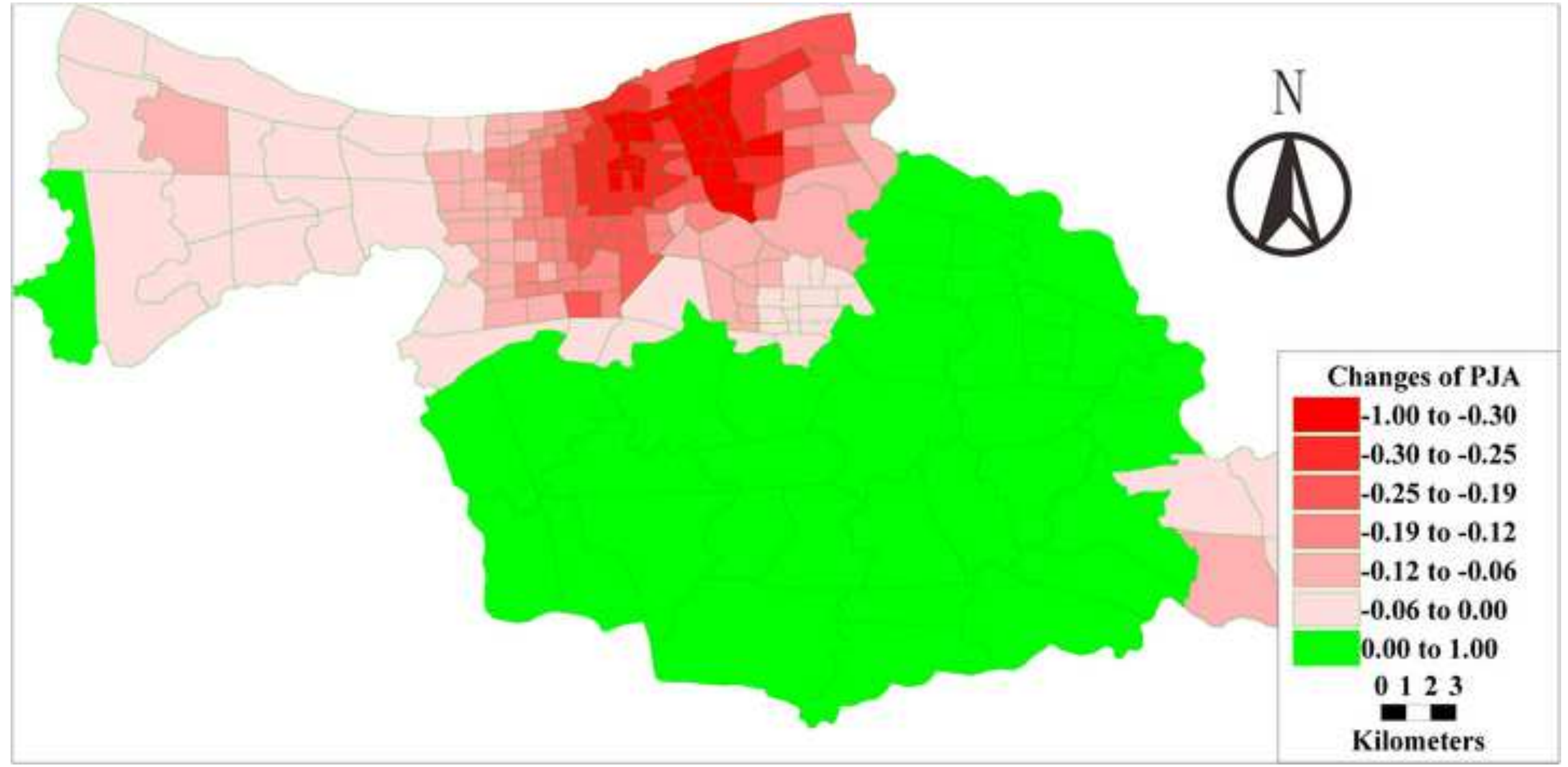




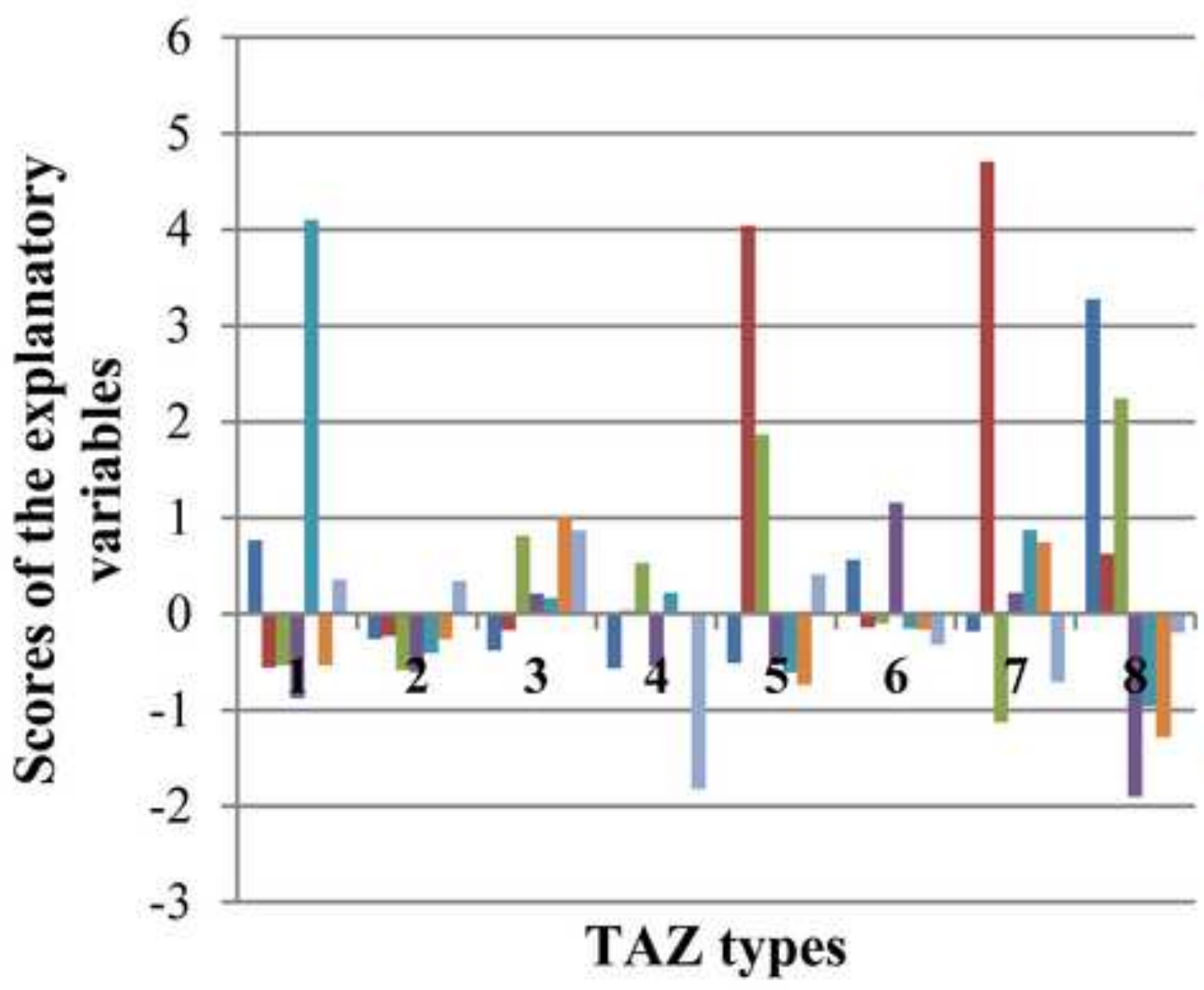

- Regional Size

- Industrial Job

netail Job and Bus

- Population

Government Job

- Street Design

Infrastructure Accessibility 


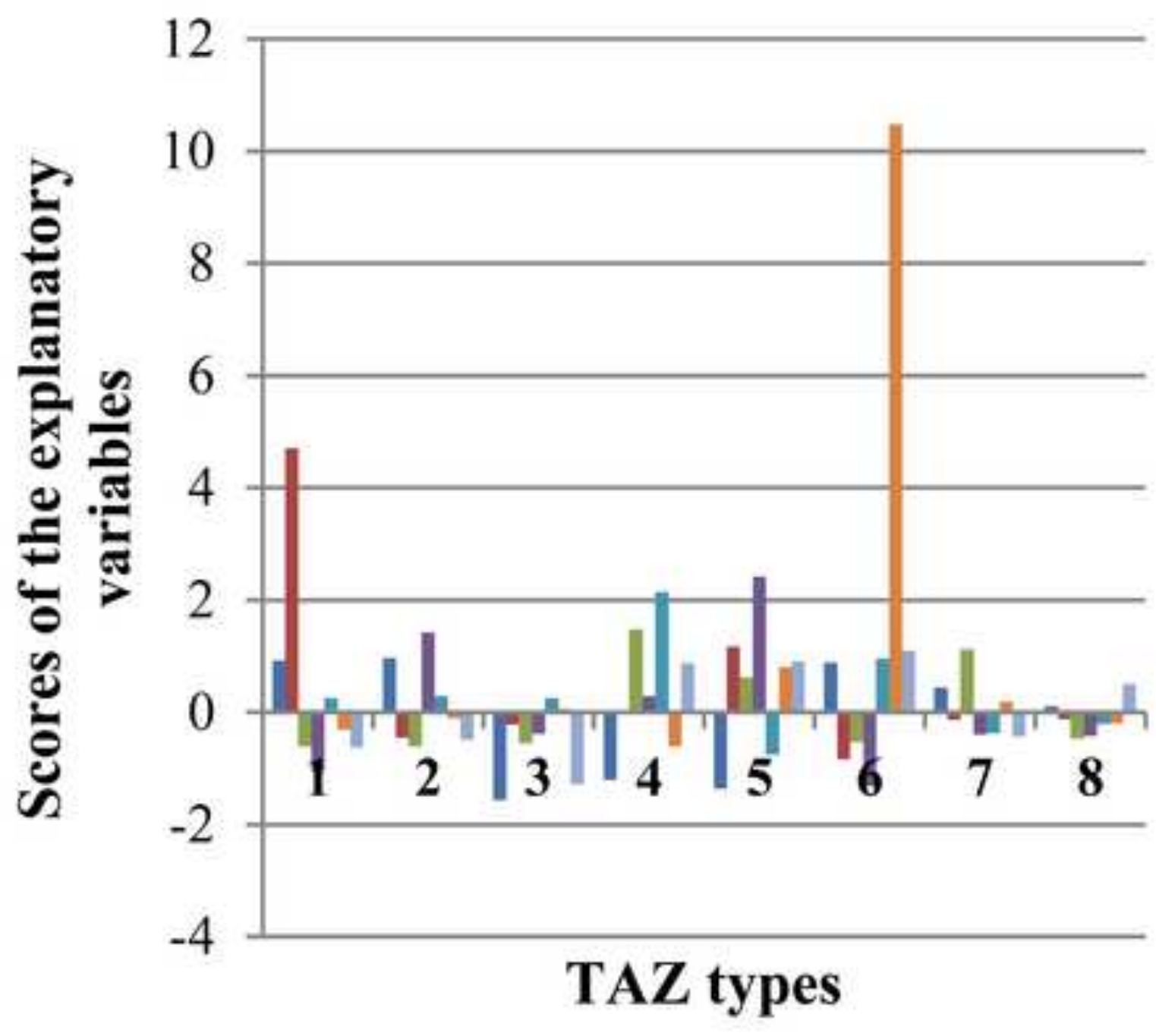

- CBD Accessibility

netail Job

andustrial Job

nopulation

- Street Design and Bus

a Government Job

Infrastructure Accessibility 


\section{Tables}

Table 1 Description of the characteristics of three scenarios

\begin{tabular}{cccc}
\hline Scenarios & Policy description & Initial year & Final year \\
\hline A & Business as usual & 2010 & 2025 \\
C10 & Scenario A plus 10 Chinese Yuan (CNY) cordon toll & 2020 & 2025 \\
C20 & Scenario A plus 20 CNY cordon toll & 2020 & 2025 \\
\hline
\end{tabular}

Table 2 Components of the Jiangyin integrated model

\begin{tabular}{cl}
\hline Category & Main Components \\
\hline $\begin{array}{c}\text { Land Use } \\
\text { Sectors }\end{array}$ & $\begin{array}{l}\text { Industrial job, retail job, government job, entertainment job, health job, education job, population, industrial land, retail } \\
\text { land, residential land, office land, health land, education land, and entertainment land }\end{array}$ \\
\hline $\begin{array}{c}\text { Physical } \\
\text { Supply }\end{array}$ & Road network, conventional bus network, and cycling \& walking lanes \\
\hline $\begin{array}{c}\text { Operative } \\
\text { Supply }\end{array}$ & Public transport, private car, walk, and bike \\
\hline
\end{tabular}

Table 3 Summary statistics for all raw measures of built environment

\begin{tabular}{|c|c|c|c|c|}
\hline $5 \mathrm{Ds}$ & Variable & Unit of measure & Mean & Std. Dev. \\
\hline \multirow{9}{*}{ Density } & Population Density & Count $/ \mathrm{km}^{2}$ & 5959.80 & 8211.02 \\
\hline & Industrial Jobs Density & Count $/ \mathrm{km}^{2}$ & 1409.61 & 1679.58 \\
\hline & Government Jobs Density & Count $/ \mathrm{km}^{2}$ & 192.58 & 554.71 \\
\hline & Retail Jobs Density & Count $/ \mathrm{km}^{2}$ & 1977.65 & 3557.50 \\
\hline & Population & Count & 7257.31 & 12851.69 \\
\hline & Number of Industrial Jobs & Count & 3536.99 & 5872.37 \\
\hline & Number of Government Jobs & Count & 197.36 & 414.31 \\
\hline & Number of Retail Jobs & Count & 2634.82 & 5298.29 \\
\hline & Regional Size & $\mathrm{km}^{2}$ & 3.05 & 4.93 \\
\hline \multirow{3}{*}{ Diversity } & Industrial Size & $\mathrm{km}^{2}$ & 0.49 & 0.82 \\
\hline & Retail Size & $\mathrm{km}^{2}$ & 0.08 & 0.17 \\
\hline & Residential Size & $\mathrm{km}^{2}$ & 0.27 & 0.53 \\
\hline \multirow{3}{*}{ Street Design } & Number of Intersections & Count & 5.68 & 3.39 \\
\hline & Length of Street & $\mathrm{km}$ & 6.41 & 6.62 \\
\hline & Density of Street & $\mathrm{km} / \mathrm{km}^{2}$ & 5.01 & 2.88 \\
\hline \multirow{4}{*}{ Destination Accessibility } & Distance to Central Business District (CBD) & $\mathrm{km}$ & 15.90 & 13.72 \\
\hline & Distance to Commercial Centers & $\mathrm{km}$ & 19.21 & 15.26 \\
\hline & Distance to School & $\mathrm{km}$ & 19.86 & 14.42 \\
\hline & Distance to Hospital & $\mathrm{km}$ & 29.27 & 18.41 \\
\hline Distance to Transit & Number of Bus Stations & Count & 1.99 & 2.01 \\
\hline
\end{tabular}

Table 4 The values of the cluster centroids of eight TAZ types within the road pricing region

\begin{tabular}{ccccccccc}
\hline \multirow{2}{*}{ Essential Elements } & \multicolumn{9}{c}{ Cluster } \\
\cline { 2 - 8 } & TAZ 1 & TAZ 2 & TAZ 3 & TAZ 4 & TAZ 5 & TAZ 6 & TAZ 7 & TAZ 8 \\
\hline Regional Size & 0.766 & -0.262 & -0.381 & -0.568 & -0.513 & 0.557 & -0.184 & 3.274 \\
Industrial Job & -0.559 & -0.231 & -0.167 & 0.030 & 4.034 & -0.143 & 4.709 & 0.623 \\
Retail Job and Bus & -0.534 & -0.586 & 0.809 & 0.524 & 1.862 & -0.095 & -1.130 & 2.241 \\
Population & -0.875 & -0.608 & 0.210 & -0.548 & -0.498 & 1.153 & 0.216 & -1.903 \\
Government Job & 4.100 & -0.409 & 0.161 & 0.218 & -0.614 & -0.149 & 0.874 & -0.964 \\
Street Design & -0.534 & -0.264 & 1.007 & -0.002 & -0.740 & -0.163 & 0.746 & -1.278 \\
Infrastructure Accessibility & 0.356 & 0.341 & 0.867 & -1.821 & 0.409 & -0.318 & -0.709 & -0.193 \\
Counts & 2 & 20 & 10 & 6 & 1 & 15 & 1 & 1 \\
Percentage of all & $4 \%$ & $36 \%$ & $18 \%$ & $11 \%$ & $2 \%$ & $27 \%$ & $2 \%$ & $2 \%$ \\
\hline
\end{tabular}


Table 5 The values of the cluster centroids of eight TAZ types outside the road pricing area

\begin{tabular}{ccccccccc}
\hline \multirow{2}{*}{ Essential Elements } & \multicolumn{9}{c}{ Cluster } \\
\cline { 2 - 8 } & TAZ 1 & TAZ 2 & TAZ 3 & TAZ 4 & TAZ 5 & TAZ 6 & TAZ 7 & TAZ 8 \\
\hline CBD Accessibility & 0.926 & 0.971 & -1.569 & -1.201 & -1.358 & 0.880 & 0.444 & 0.108 \\
Retail Job & 4.702 & -0.458 & -0.215 & 0.009 & 1.166 & -0.830 & -0.131 & -0.124 \\
Industrial Job & -0.614 & -0.608 & -0.547 & 1.475 & 0.617 & -0.530 & 1.129 & -0.468 \\
Population & -1.049 & 1.417 & -0.379 & 0.286 & 2.408 & -1.316 & -0.399 & -0.421 \\
Street Design and Bus & 0.256 & 0.284 & 0.249 & 2.143 & -0.749 & 0.953 & -0.369 & -0.208 \\
Government Job & -0.308 & -0.112 & 0.058 & -0.612 & 0.798 & 10.476 & 0.191 & -0.186 \\
Infrastructure Accessibility & -0.615 & -0.493 & -1.277 & 0.876 & 0.911 & 1.094 & -0.424 & 0.505 \\
Counts & 5 & 29 & 22 & 12 & 10 & 1 & 44 & 86 \\
Percentage of all & $2 \%$ & $14 \%$ & $11 \%$ & $6 \%$ & $5 \%$ & $0 \%$ & $21 \%$ & $41 \%$ \\
\hline
\end{tabular}

Table 6 Regression results for potential job accessibility and its changes under different toll level

\begin{tabular}{|c|c|c|c|c|}
\hline \multirow{2}{*}{ Explanatory Variables } & \multicolumn{4}{|c|}{ Spatial Lag Model } \\
\hline & $\mathrm{C} 10$ & $\mathrm{C} 20$ & C10-A & $\mathrm{C} 20-\mathrm{A}$ \\
\hline \multirow{2}{*}{$\operatorname{Phi}(\phi)$} & $0.651^{* * *}$ & $0.517 * * *$ & $-0.540^{* * *}$ & $-0.321 * * *$ \\
\hline & $(12.162)$ & $(9.643)$ & $(-4.562)$ & $(-2.818)$ \\
\hline \multirow{2}{*}{ Constant } & $8.396^{* * *}$ & $11.478 * * *$ & $-2.689 * * *$ & $-5.351 * * *$ \\
\hline & (4.297) & $(5.984)$ & $(-8.648)$ & $(-12.258)$ \\
\hline \multirow{2}{*}{$\begin{array}{c}\text { Within the Road Pricing } \\
\text { Region }\end{array}$} & 16.918 *** & $24.414 * * *$ & $9.614 * * *$ & $16.930 * * *$ \\
\hline & $(12.333)$ & $(18.056)$ & $(12.160)$ & $(16.316)$ \\
\hline \multirow{2}{*}{ Distance to CBD } & $-1.614 * * *$ & $-1.189 * *$ & $1.856 * * *$ & $3.768 * * *$ \\
\hline & $(-2.618)$ & $(-2.045)$ & $(6.396)$ & $(9.968)$ \\
\hline \multirow{2}{*}{ Population } & 0.551 & 0.345 & 0.314 & $0.555^{*}$ \\
\hline & $(1.271)$ & $(0.831)$ & $(1.224)$ & $(1.672)$ \\
\hline \multirow{2}{*}{ Retail Job } & $1.732 * * *$ & $2.050 * * *$ & 0.291 & $0.730^{* *}$ \\
\hline & $(4.078)$ & $(5.019)$ & $(1.145)$ & $(2.244)$ \\
\hline \multirow{2}{*}{ Industrial Job } & $1.961 * * *$ & $2.312 * * *$ & 0.180 & $0.735^{* *}$ \\
\hline & $(4.440)$ & $(5.442)$ & $(0.682)$ & $(2.175)$ \\
\hline \multirow{2}{*}{ Government Job } & $1.049^{* *}$ & 0.699 & $-0.838 * * *$ & $-1.408 * * *$ \\
\hline & $(2.332)$ & $(1.607)$ & $(-3.152)$ & $(-4.121)$ \\
\hline \multirow{2}{*}{ Street Design and Bus } & $1.887 * * *$ & $1.578^{* * *}$ & 0.056 & -0.223 \\
\hline & $(4.410)$ & $(3.833)$ & $(0.217)$ & $(-0.680)$ \\
\hline Distance to & 0.165 & 0.230 & -0.149 & -0.207 \\
\hline Infrastructure & $(0.383)$ & $(0.552)$ & $(-0.575)$ & $(-0.625)$ \\
\hline
\end{tabular}

Note: Dependent Variable: Potential job accessibility and its changes (Scenario C-Scenario A); z-statistics are in parenthesis.

* Significant at $90 \%$, ** Significant at $95 \%$, *** Significant at $99 \%$.

Table 7 Change in PJA indicators of different TAZ types within the cordon between Scenarios A and C

\begin{tabular}{ccc}
\hline Cluster & Charge 10 CNY & Charge 20 CNY \\
\hline 1 & $\mathbf{3 . 7 8 \%}$ & $\mathbf{6 . 2 9 \%}$ \\
2 & $10.07 \%$ & $15.25 \%$ \\
3 & $\mathbf{1 2 . 0 1 \%}$ & $\mathbf{1 6 . 5 4 \%}$ \\
4 & $8.43 \%$ & $13.97 \%$ \\
5 & $\mathbf{1 5 . 0 8 \%}$ & $\mathbf{2 2 . 4 8 \%}$ \\
6 & $7.86 \%$ & $12.40 \%$ \\
7 & $7.07 \%$ & $13.02 \%$ \\
8 & $\mathbf{1 . 6 3 \%}$ & $\mathbf{1 0 . 5 4 \%}$ \\
\hline
\end{tabular}

The bold values show the TAZ types most affected by the road pricing policy, while the values which are displayed in dark and bold indicate the least positively affected TAZ types.

Table 8 Change in PJA indicators of different TAZ types outside the cordon between Scenarios A and C

\begin{tabular}{ccc}
\hline \multirow{2}{*}{ Cluster } & Charge 10 CNY & Charge 20 CNY \\
& & \\
\hline 1 & $-0.08 \%$ & $\mathbf{2 . 8 1 \%}$ \\
2 & $\mathbf{- 1 0 . 9 4 \%}$ & $\mathbf{- 2 1 . 4 1 \%}$ \\
3 & $\mathbf{1 . 0 6 \%}$ & $0.33 \%$ \\
\hline
\end{tabular}




\begin{tabular}{ccc}
\hline Cluster & Charge 10 CNY & Charge 20 CNY \\
\hline 4 & $\mathbf{1 . 3 1 \%}$ & $\mathbf{1 . 4 3 \%}$ \\
5 & $0.65 \%$ & $0.76 \%$ \\
6 & $\mathbf{- 2 3 . 2 7 \%}$ & $\mathbf{- 4 4 . 1 6 \%}$ \\
7 & $-6.03 \%$ & $-10.49 \%$ \\
8 & $-7.04 \%$ & $-13.74 \%$ \\
\hline
\end{tabular}

The bold values display the most positively affected TAZ types, while the values displayed in dark and bold express the most adversely affected TAZ types. 